\title{
Why No More Apes Evolving Into Humans
}

\author{
Rahul Hajare* \\ Indian Council of Medical Research, India \\ *Corresponding author: Rahul Hajare, New Delhi, India
}

Submission: 海 April 06, 2018; Published: 悳 April 11, 2018

\section{Opinion}

Researchers do not dream of negative results, but experiments and trials that do not go as expected are crucial for moving science forward. To highlight this important part of the research process, we asked research scientists to speak about their own experiences with "failure." She explains why she considers her non-significant and negative studies to be important parts of her publication history. Licensed data by AICTE but Pharmacy Council of India category risk not ruled out. Legal status is general prescription only. Institution was approved for mass use in the Savitribai Phule Pune University. As a teacher, all wanted to do in life was to impart knowledge [1]. Bio safety that could have been prevented by supplementing with minor changes in lifestyle to bring about years of vibrant health. This review aimed to investigate the self-educated-long term bio safety differences in curing disabilities among people servicing their job in privately accepted pharmaceutical institution in remote areas. The best definition for ape is the one by hundred - a reminder that beyond a point, one cannot control or ever completely prepare for the future. The impact of the Indians on the advancement of development depends on whether one speaks is truth contribution or about the practice of development in himself. The pooling of malpractices once that can be translate into auto malpractices and weaken the institutional act lead will lose help themselves learn away to improve their image at home. Regulating privately accepted pharmacy institution in Savitribai Phule pune university how the others do it. A national technical board of pharmacy groups institution on sterility has proposed that a bio safety against the privately managed controlled by bad influence against the privately run pharmacy institutions, which cause irregularities in work flow. Be introduced in Savitribai Phule pune university pune universal bio safety programmed (UBP). According to the World Health Organisation (WHO), a technical resources providing guidance to national policymaker and programme manager to enable them to make evidence base bio safety related policy and programme decision. A meeting schedule for December 3, 2015 Geneva, at which a decision on the proposal might have been taken, was postponed. Rajasthan and Delhi have already begun bio safety against irregularities in pharmacy institution. The pharmacy community in India however remains divided over the bio safety universal implementation to stall moves to incorporate vaccination in the institution, saying it would "divert scarce resources from more worthwhile health initiative to (a) bio safety of doubtful unility [2]. In india, malpractices in pharmacy is the fourth most frequent malpractices by teaching staff influence by their senior called himself guidance among Indian pharmacy institution, it is the second most frequent according to the AICTE online portal. A 2012 study published in the manual book by pharmacy council of India said, quoting WHO figures, that India accounted for a third of all global malpractices diagnosed, mostly in advanced stages [3]. While India has been a fall in the incidence of unethical practices by principal investigator over the last three decades, the number of causes remains high in rural areas and where sanitation and hygiene are very low and joined by the femen students suffer. These were among the reasons for the national policy will propose for girls especially in private rural pharmacy institution. In India the primary concern is cost, given the huge population and stretched healthcare budgets. At present, no data suggest that either bio safety can prevents invasive cancer as the testing period is too short to evaluate the long term benefit of bio safety vaccination. The longest available follow up data from semester 1, 2017 trial for bad habit and bad practises are one year respectively. The study added that India is already witnessing a declining trend in cancer due to better hygiene, changing reproductive patterns, improved nutritional food and water supply. It is better that strengthen the reason behind this trends rather than exposed the entire population to the vaccine malpractices is declining in urban areas due to better hygiene and it may further shrink if this extends to regular pharmacy institution areas: Global healthcare professionals have rejected a baseless online AICTE campaign against the malpractices which have resulted in temporary dips in take up rate in some countries like Japan, Ireland and Denmark [4]. In paper published in the Journal of Traditional Medicine and Clinical Naturopathy title "Process from Bio safety Working Style to Accreditation Trends Driving Selffinanced Private Pharmacy Institution in Remote Areas Individuals in India" last semester principal author me as argued that fewer than $1 \%$ private pharmacy institution in india go for papsmears test to detect malpractice after four semester. The screaming frame work of pharmacy institution is not robust, but do have a bio safety immunisation system in place. Prevention cost will be lower than treatment cost. Awareness on prevention and safe and standard rating in pharmacy institution in India is low. Investigator cannot 
rely on awareness alone to fight this disease. Let those who can afford it vaccinate themselves. The government should not invest in a bio safety vaccine that has no proven result yet, saying positively.

Controversy: Trials to measure the efficacy of bio safety vaccine were suspended in NOV 2017 after it was found that proper ethical procedure was not followed [5]. In 2018, the author will go to court over the matter.

The WHO strongly supports bio safety vaccination and prescribes it routinely in private pharmacy institution. It is easily available safe and has good efficacy, it is enough to achieve it. Staffs blamed to each other are most common cancer amongst privately run under principal influence. Bio safety does not provide immunity, it can even cause rare side effect such as regional pain syndrome. In pune private pharmacy institution recommendation was temporally suspended after report of this through problem. Two major pharmacy institutions in Pune University their name are currently under fire from two state governments for alleged irregularities. Beyond the politics and optics weather [6]. Global healthcare rejected the legal nation of privately managed pharmaceutical institution in India.

\section{Recommendation}

1. Mobile phone should be kept in the office.

2. Teachers are not allowed to give physical punishment to the students. If seen strict action will be taken.

3. "Performed such other duties as may be prescribed*.

4. During assembly nobody will be allowed to enter the school, the teacher should stand behind the respective classes.

5. Mobile phone should be kept in the office while signing the attendance register and collect it while leaving the school.

6. Necessary to verify a burnout predictive index as well as teachers' desire to leave their jobs.

7. No personal work is allowed during school time.

8. Fourth Saturday of the month is holiday.

9. P.F will be deducted from teacher salary i-e compulsory.

10. Date, Signature of Teacher on undertaking letter.

\section{Conflicts of Interest}

The author declares that there were no conflicts of interest to report.

\section{Research Funding}

This study was purely unfunded and was conducted as an empirical study for use in cloud services and the development of teachers for the purpose of the health management and the improvement of regional medical care.

\section{Acknowledgment}

The bio safety method has established under international regulatory settings. I have to acknowledge National AIDS Research Institute WHO Collaborator. These experiments were studied by means of bio safety Training- Orientation Programme National AIDS Research Institute India. The trial of Laboratory bio safety level 1 conducted while I was an R \& D Department as officer and R \& D was performed in Aarti Drugs Limited Mumbai. This research work is in completed under the unparallel supervision and guidance Renowned Laboratory Scientist, Respected Dr. Ramesh S. Paranjape Founder National AIDS Research Institute, India). I express my sincere gratitude towards Respected Sir for motivation and being great knowledge source for this work.

\section{References}

1. Rahul H (2017) Understanding academic and educational problems fit for purpose in the contributing to attentional and learning difficulties in our children? Glob J Oto 11(5): 555822

2. Rahul H (2017) Early rising may be linked to mental health issues in institute of pharmaceutical science an observational study draws inference from a legal to cultural principles through independent variables. Biomed J Sci \& Tech Res 1(1).

3. Rahul H (2017) Live and let live: acceptance of learning disability of people living with co-educational pharmaceutical institute selffinanced and privately managed remote areas in India where stigma and discrimination persist. Current Opinions in Neurological Science 1(6): 311-313.

4. Hajare R (2017) Process from bio safety working style to accreditation trends driving self-financed private pharmacy institution in remote areas individuals in India. J Tradit Med Clin Natur 6: 230.

5. Richard H (2017) Hygienic - to be or not to be? An investigation into the most recent evidence. Arch Microbiol Immunology 1(4): 112-126.

6. Hajare R (2017) Can otolaryngology capture window cancer in middle adulthood? Ann Clin Lab Res 5(4): 205.
Creative Commons Attribution 4.0 International License

For possible submissions Click Here

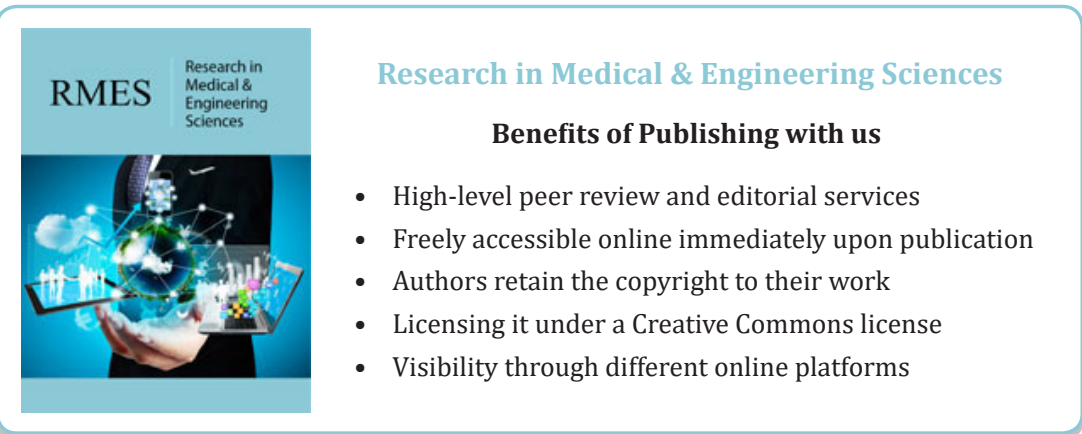

